\title{
Product Ownership of a Legacy Institutional Repository
}

A Case Study on Revitalizing an Aging Service

Mikala Narlock and Don Brower

ABSTRACT

Many academic libraries have developed and/or purchased digital systems over the years, including digital collection platforms, institutional repositories, and other online tools on which users depend. At Hesburgh Libraries, as with other institutions, some of these systems have aged without strong guidance and resulted in stale services and technology. This case study will explore the lengthy process of stewarding an aging service that satisfies critical external needs. Starting with a brief literature review and institutional context, the authors will examine how the current product owners have embraced the role of maintainers, charting a future direction by defining a clear vision for the service, articulating firm boundaries, and prioritizing small changes. The authors will conclude by reflecting on lessons learned and discussing potential future work, both at the institutional and professional level.

\section{INTRODUCTION}

Our home-grown institutional repository (IR) began almost a decade ago with enthusiasm and promise, driven by an eagerness to meet as many use cases as possible. Over time, the code grew unwieldy, personnel transitioned into new roles, and new priorities emerged, leaving few individuals to manage the repository, allocate resources, articulate priorities, or advocate for user needs. This in turn left the system underutilized and undervalued. In mid-2019, two product owners (POs) at Hesburgh Libraries, University of Notre Dame were named to oversee the service and tasked with determining how the service should continue, if at all. The POs began by evaluating the service, current commitments, and benefits, and identifying potential on-campus adopters of the service. After agreeing the service should continue, the POs started the lengthy process of turning the metaphorical ship, prioritizing modest adjustments that would have large payoffs. $^{1}$

\section{SELECTED LITERATURE REVIEW}

Since the 2003 seminal article by Clifford Lynch, much has been authored on the topic of institutional repositories as academic libraries and archives have flocked to create their own. ${ }^{2} \mathrm{~A}$ complete literature review is beyond the scope of this case study: institutional repositories have contended and continue to contend with a wide variety of challenges, including legal, ethical, and socio-technical challenges. ${ }^{3}$ While the lessons presented in this case study can apply to a wide variety of legacy services, a brief overview of some of the literature surrounding IRs is crucial to understanding the challenges the authors were presented as product owners.

Broadly defined "as systems and service models designed to collect, organize, store, share, and preserve an institution's digital information or knowledge assets worthy of such investment," libraries and archives flocked to build the "essential infrastructure for scholarship in the digital

Mikala Narlock (mnarlock@nd.edu) is Digital Collections Strategy Librarian, University of Notre Dame. Don Brower (마ower@nd.edu) is Digital Projects Lead, University of Notre Dame. (C) 2021. 
age."4 Operating under the assumption that faculty members would flock to the service to deposit their works, IRs were promised to solve many problems, including supporting open access publishing and digital asset management. ${ }^{5}$

As articulated by Dorothea Salo, however, the Field of Dreams model ("build it and they will come") was insufficient as repositories often failed to meet changing user needs and expectations while heavily employing library jargon that was foreign to faculty members. ${ }^{6}$ Moreover, as identified by Kim, some IRs struggle to even be known to their users, while also grappling with concerns of trust. ${ }^{7}$ Other problems that have plagued repositories include limited adoption rates, restricted resources to support digitization of analog materials for faculty that operate in both analog and digital media, failing support from fellow library colleagues, and inconsistent and incomplete metadata. ${ }^{8}$ Salo warned more than a decade ago that high-level library administrative support would be necessary to empower repository managers to enact lasting and substantive change, and recent studies echo these concerns. ${ }^{9}$

Libraries have slowly started to serve faculty on their terms, such as by creating automated processes for populating IRs, streamlining content deposits, experimenting with metadata harvesting features to provide increased access, and building more tools to integrate directly with the research lifecycle. ${ }^{10}$ However, these new technologies and services may be out of reach for many institutions. In addition to limited resources, some institutions are grappling with a legacy system that is incompatible with newer code, leaving these institutions in a feature desert, reliant on aging technology and cumbersome deposit processes. ${ }^{11}$ Moreover, even in an institution where resources might be more readily available for licensing or purchasing newer technology, early forks of open-source code or otherwise deprecated components might make migration to newer platforms extremely difficult, if not impossible, without extensive infrastructure improvements.

Lastly, as libraries grappled with some of the issues mentioned above and options for repositories continued to proliferate, many institutions struggled to clearly articulate boundaries around their digital library holdings. Confusion between digital collections, scholarly content, e-resources, and other digital materials resulted in some institutions having too many options to store content, leaving internal and external stakeholders confused as to where to discover and distribute materials; conversely, other institutions have few options, and a wide variety of content is pigeonholed imperfectly into a single repository. ${ }^{12}$ In both situations, developing repositories with vague content scopes can be exceedingly difficult, as a restrictive scope can stifle development, while an overly inclusive approach results in too many use cases and competing stakeholder interests to effectively prioritize feature development.

\section{LOCAL CONTEXT}

Our institutional repository at the University of Notre Dame, managed by Hesburgh Libraries employees, suffered from many problems that affected our locally built code: limited adoption and awareness on campus; aging technology that made adding new features a monumental, if not impossible, task; and an overly broad scope (and a simultaneous proliferation of other digital collection tools). While the detailed history of this repository is beyond the scope of this paper, a brief overview of the development provides critical context. Additionally, the technical details and implementation particulars will not be discussed, as this case study transcends specific software frustrations and will resonate with many institutions regardless. 
In 2012, after a failed attempt to launch a repository in the early 2000's, consortial development of our IR began in an open-source community. In 2014, an early implementation of the product was envisioned to be a unified digital library service that would provide support to many different stakeholders. This included a plan for a single location for researchers to share their scholarly work, research outputs, and research data, as well as for the University Libraries to provide access to digitized rare and archival holdings.

As development continued on the homegrown service, features were implemented to serve the numerous purposes mentioned above. This included components of an institutional repository, such as a self-deposit interface, customizable access levels, and a proof-of-concept researcher profile system. Over time support for browsing digital collections was added, namely the development of the work type "collection," which allowed curators to create a landing page for their collection and customize it with a representative image. Development continued in a somewhat sporadic fashion, often aligning at the intersection of "What is easy?" and "What is needed?" as technical staff continued growing the open-source code.

As content was added to the system, stemming from special collections, various campus partners, and electronic thesis and dissertation (ETD) deposits, additional use cases emerged and were added to the scope of the repository. The system quickly grew cumbersome and difficult to work with. In short, the repository struggled with the challenges of many open-source technologies. The struggle was compounded by decreasing resources, an overly inclusive scope, limited adoptionboth with external faculty as well as library faculty and staff-and consortial development that introduced features extraneous to local campus needs. While our repository did many different things, it failed to do any one well.

After falling short of meeting the expectations for digital collections, particularly with regards to browsing and displaying objects, the library applied for, and received, a three-year Mellon grant. ${ }^{13}$ This grant, a collaboration with the Snite Museum of Art, University of Notre Dame, was initially sought to improve upon the existing repository and to build the infrastructure necessary to support the online display of collective cultural heritage materials and facilitate serendipitous discovery for patrons. However, soon into the grant, it became clear that creating an entirely new system for digital collections would be not only easier to build and maintain, but also better suited to meet the specific needs of digital collections as articulated by campus partners.

\section{FIRST THINGS FIRST: WHAT IS OUR IR?}

Around the same time this shift was announced, two individuals were appointed to serve as product owners (POs) of the repository. While exact duties vary between institutions, POs are responsible for liaising with users, managing the product backlog, directing development, communicating with a wide variety of stakeholders, resolving issue tickets, and guiding the overall direction of the product. ${ }^{14}$ The POs were tasked with making this amorphous, oft-critiqued service usable while dealing with uncertain resources and competing institutional priorities. With the change in grant objectives mentioned above, namely the desire to develop a new repository instead of contending with the legacy code, the option was presented to retire the repository and direct users to other systems that could sufficiently meet their needs, such as discipline specific repositories, general purpose repositories, or even online cloud storage. The POs recognized that continuing the system due solely to sunk costs was a fallacy: if the service was too cumbersome to 
maintain with even nominal use, the return on investment would be abysmal and ultimately prevent the library from investing resources more appropriately.

In order to evaluate the service, the POs considered active commitments and ongoing partnerships tied to the service. In particular, several centers and departments on campus had utilized the system to capture citations and demonstrate their impact. Additionally, after conversations with library liaisons, it became apparent that there was great value in providing the campus with a discipline-agnostic repository that allows deposition of, provides access to, and preserves scholarly outputs that might otherwise be lost. While the POs recognized that faculty adoption or even awareness of the service was limited, they realized there were several campusspecific features that were useful to local champions, including flexible access controls at the record and file levels, as well as a customized ETD workflow that served the graduate school, internal technical services, and the students and faculty required to interact with the system. Acknowledging that the system and related services were still critical, the POs prioritized making sure the system remained useful: maintaining the legacy repository would cost valuable time and resources and would need to overcome the resentment that many internal stakeholders had developed over the years.

After deciding the system was worth maintaining, it was necessary to explicitly narrow the scope of the service, which had broadened over time in an ad hoc manner: as other services were turned off, leaving various digital content to find a new location, our institutional repository was often leveraged to host the content, even when support for the needs of niche content was poor at best.

When considering the future of the repository, several key use cases emerged, including the ETD support provided to the graduate school as mentioned above. While the service had done many things acceptably, the strength was in the support for scholarship: the customized access levels, self-deposit interface, and robust preservation capabilities were frequently lauded as the highlights of the service to internal and external stakeholders. These considerations, combined with the eventual migration of digitized rare and unique materials to the new Mellon-funded platform, resulted in rebranding and redefining the service as exclusively focused on scholarly outputs. With the goal of best supporting the teaching and research mission of the university, the directional force became how to (re)build the service as a trusted, useful, and integral repository for campus scholars to provide access to their research outputs.

\section{MISSION (AND VISION) CRITICAL}

Operating under the guiding principles of usefulness, usability, and transparency, the first task after redefining and rearticulating the scope of the service was to keep the service operational. However, with the recognition that maintenance alone, while critical, would not lead to an enhanced reputation on campus, it was important to continue charting a forward direction. The product owners were given the freedom to articulate their ideal mission statement. To complement the vision of the repository as both trusted and integral, the POs further defined the mission statement in three key areas: to increase the impact of campus researchers, scholars, and departments; to advance new research by facilitating access to scholarship in all forms; and to serve as active campus partners in the research lifecycle.

While these statements are far from innovative or revolutionary, it was essential for moving the service forward. In fact, these sentences were carefully crafted over the course of a month, during which time the product owners drafted the language, compared it with peer and aspirational peer 
institutions, and solicited feedback from trusted internal colleagues before sharing it more broadly. This time-consuming process was critical for success, however: with the knowledge that these words would serve as the foundation for prioritizing feature requests and advocating for resources, the POs wanted to establish both the repository and themselves in their new role. This clarity in mission was also important for grappling with legacy emotional and mental frustrations that lingered towards the system, as the POs had a strong, unified foundation to advocate for resources and the service as a whole. Relatedly, these mission and vision statements provided critical and consistent talking points, which were leveraged in presentations to internal stakeholders, provided to librarians as messaging for the liaison faculty, and useful in short communications to teaching professors, research faculty, and department administrators.

\section{CLEAR AND PRESENT BOUNDARIES}

In rebranding the repository, it also became clear that firm boundaries would be instrumental in attaining success. In addition to narrowly focusing feature development on supporting research and scholarly outputs, the POs also scaled back goals for adoption, intentionally excluded digital collection features, and identified features that were patently unattainable in the short term.

The repository was often seen as a failure locally due to limited adoption and an incomplete record of the academic outputs of campus, reflecting concerns of IRs more generally. ${ }^{15}$ Combatting this narrative required a clear articulation and acceptance of the fact that the institutional repository, regardless of how seamlessly integrated or easy to use, would never be absolutely comprehensive or the authoritative record of our researchers and scholars. With limited resources and a current technical infrastructure in which it is difficult to incorporate automatic harvesting mechanisms, any effort to make the repository comprehensive would be impractical, unrealistic, and a waste of limited resources. Instead, by focusing efforts on making the repository useful and refraining from being yet another requirement for an already overwhelmed faculty member or graduate student, the service can be improved to meet the unique needs of campus faculty, serving as a more viable option for those who need it. ${ }^{16}$ Similarly, because there is less concern with filling the repository and increasing usage statistics and more on what the patron needs, the POs have been able to develop robust partnerships with stakeholders, leading to champions in research centers, labs, departments, and other administrative units across campus. This has helped scholars demonstrate the impact of their work, which in turn led to more partnerships with other campus centers, as champions began to advocate for the service to colleagues facing similar challenges across the university. In this way, decreasing the effort to fill the repository has actually increased holdings and driven more traffic to the site: by focusing on useful offerings and decreasing the burden on ourselves to create a comprehensive research repository, the POs have been able to prove the value of a discipline-agnostic approach to internal and external stakeholders.

An additional, and extremely beneficial, boundary was intentionally excluding library-owned digital collections from the repository's collecting and feature-development scope. The POs received little pushback from internal users on this change: the repository had been the de facto scholarly and research repository for nearly five years, as it was patently clear that supporting digital collections had been more of an afterthought, with limited features built to support curators and users in creating and interacting with rare and archival materials. In fact, internal colleagues supported this change wholeheartedly, as the POs volunteered to continue providing access to the extant digital content in the IR as the Mellon grant-funded site was built. While this 
direction had already been understood by individuals across the organization, it was helpful to clearly articulate the new boundaries in open forums for internal stakeholders, communication through a library-wide listserv, and repetition in smaller meetings. By articulating this new boundary clearly and repeating it frequently in different methods of communication, the POs had the authority to reject feature requests that were explicitly in support of rare and archival materials. With a clear focus on collecting and providing access to scholarly and research outputs, niche metadata fields, advanced browsing features, and robust collection landing pages were identified as unnecessary, as they were scoped for the Mellon-funded platform, and internal colleagues quickly embraced this boundary.

The final, crucial boundary, also related to feature requests, was to clearly define requests that were impossible to accommodate in the current technical infrastructure. As mentioned earlier, the POs focused first on maintenance: by updating code, critically evaluating the service and existing commitments, and charting a future direction, the POs could more effectively steward the project. This also meant revisiting previous feature requests, and even technical promises, in order to set more reasonable expectations on what the service would, and would not, be able to support in the coming years. With limited resources, advanced features such as research profiles - a frequent request from internal allies-was beyond the current capabilities with the aging technical stack. Moreover, a feature-rich repository would be essentially useless if users' basic expectations were left unmet: a cumbersome deposit interface, limited upload support, and confusing language throughout the site were more pressing issues, as they prevented users from even engaging with the site for any amount of time. By resolving these limitations and generating awareness of the repository, the POs could better serve not only current campus partners, but also future users, as an increase in adoption and use would lead to more resources to develop advanced features. Instead of planning a new outfit for the proverbial patient, it was more important to stop the bleeding.

By adopting firm boundaries, the POs were able to scope developer work, prioritize maintenance and modest feature development, and even deny implementation of previously requested features that were no longer relevant to the repository or would be unattainable in the coming years. The POs could explicitly drop support for unused services, allow other services to limp along, and improve existing strengths. This has further helped to clarify messaging about the service and garner more support from our campus partners; instead of a malleable system that fits too many roles in a limited capacity, the POs could clearly state how the repository offers support and garner users from across campus.

\section{SMALL CHANGES, BIG REWARDS}

The last critical component of rebranding and revitalizing the institutional repository was the conscious decision to implement incremental improvements instead of large, sweeping changes. In particular, there were known frustrations with the service that were easy to start working on while the product owners expanded the user base and sought additional user feedback. Small changes to the user interface, including the addition of use metrics and color-coded access tags, received immediate attention and positive feedback from key stakeholders. Additionally, over the numerous years of development, many projects to improve the repository had stalled for various reasons. By either prioritizing the work necessary to complete the project or accepting the sunkcosts and clearing the backlog for other projects, the technical development team could build momentum, completing projects and clearing mental space for new, exciting endeavors. 
With limited resources on hand, maximizing the return on investment also included an emphasis on securing and keeping internal and external champions. Due to the limited outreach conducted early in the system's existence as well as the mediocre service offerings, many campus users were unaware of the tool, and a few were using the repository in a somewhat limited fashion. In order to build support for the service, it was critical that key users of the repository received targeted support and outreach efforts. A primary example of this was an imaging facility on campus: this unit provided a critical service to campus, yet had difficulty showing the impact of their work as many faculty members did not cite their team in publications. The facility slowly began collecting citations manually, but still struggled to publicly advertise their capabilities and show the fruits of their labor. They solved this problem by loading citation records into the repository, which became the single location where any interested faculty, staff, and students could look to see the full output of the center. While they were using the repository in a somewhat different manner than anticipated, they found the system useful and were actively directing other campus centers and institutes to the repository for similar support. In conversations with them, it became clear that a few modest changes would streamline their workflows and alleviate some cumbersome burdens. With this concentrated outreach and a minimal amount of development, the repository secured a champion that continues to advocate for the service to colleagues across campus.

Lastly, prioritizing maintenance and paying down technical debt was critical for moving the repository forward. Many software dependencies had fallen behind by several major version updates, making it difficult to add new features or consider potential migration paths to future technical solutions. While the amount of technical debt to be paid was substantial, by prioritizing a small amount of maintenance every month, the development team quickly caught up, thereby improving the overall performance of the site and providing the product owners with the flexibility to consider future technical implementations and key features to continue recruiting users.

\section{LESSONS LEARNED AND FUTURE WORK}

Moving forward, the product owners are embracing the role of maintainers. In specific reference to repositories, that includes "repairing, caring for and documenting a wide variety of knowledge systems beyond IRs to facilitate access and optimize user experience." ${ }^{17}$ The work of critically evaluating commitments, establishing clear boundaries, and reaffirming the mission of the repository is useful on a recurring basis, and will need to be continued as the repository ages. Maintaining the technical infrastructure as appropriate and conducting user experience testing to improve the service will be critical to ensuring the long-term success of the repository and the information contained therein.

Beyond the stewardship and small improvements required for maintaining the service, there is the opportunity to reconsider the role of the institutional repository, both at the local level and within the academic community. By prioritizing usefulness over comprehensiveness, the product owners made great strides in making the service accessible to patrons and actually usable. When considering the future of repositories, specifically through a lens of usefulness, it is critical to consider how future work will best serve faculty needs without overburdening librarians. Adding POs who are examining how a service will be used and what will promote the mission of the library reframes a repository from being a piece of technology to being a source of interconnections. Scholarship usually requires a level of technology different from what most campus IT departments can provide: research does not usually just deal in URLs, it requires DOIs 
and persistent identifiers; files are not just backed up, but are preserved (an active process that requires consideration for how computing will change over the coming decades). Not only is a library a place to go to look for data, but it is also a place that can help publish and deposit items, providing valuable services to connect researchers to tools and platforms to facilitate research. This is an area of service that libraries and repositories can provide.

In the relationship between libraries and technologies, innovation and maintenance, one clear challenge was the amount of emotional labor necessary to revitalize a service. The POs spent a large portion of time apologizing for previous failures, managing expectations by scaling back previous promises, and grappling with the current technical shortcomings of the service. While this is, at least in part, the role of the POs, the phenomenon of controlling expectations and handling the emotional debt that comes with broken promises and failed technologies is not localized to Hesburgh Libraries. In libraries especially, this work tends to fall to women, where they are forced to be the middle ground between technology and patron-facing librarians. ${ }^{18}$ While embracing the term "product owner" has helped to make visible and valuable the labor invested, especially that which might otherwise be overlooked, libraries writ large still need to contend with the gender divide plaguing the seeming dichotomy between innovation and maintenance. ${ }^{19}$ In fact, as libraries continue to build new technologies and support innovative research, the role of the product owners in managing legacy technologies will be crucial for success, as will embracing a culture of care and empathy. While beyond the scope of this case study, continued discussions of the gender roles often employed in library technology need to continue, especially as academic libraries embrace scrum methodology, project management, and product ownership.

\section{CONCLUSION}

In this case study, the product owners of a legacy institutional repository described methods for revitalizing a service. For the institutional repository managed by Hesburgh Libraries, there has been a noticeable increase in usage in the past six months: more deposits, higher access counts, and more support tickets tracked. It appears the efforts of the product owners are showing results. This increased usage is one more piece of evidence that a repository is more than software and more than technology: by allowing the product owners oversight of the mission and ultimate direction of the service, not to mention the freedom to engage with users on behalf of the development team, the system is in a much better position than in previous years. Despite these improvements, there is still room for growth as the POs guide the overall mission and development of the institutional repository as both a service and a system. Similarly, as more institutions contend with legacy digital technology, using POs and the methods described above may prove beneficial. There is additional work to be done, such as investigating more thoroughly the role of the repository-indeed the concept of the repository-and discussions of gender norms in technology.

\section{ENDNOTES}

${ }^{1}$ This article is based on a presentation by Don Brower and Mikala Narlock: "What to Do When Your Repository Enters Middle Age" (online presentation, Samvera Connect 2020, October 28, 2020), https://doi.org/10.7274/r0-e32v-2h81.

${ }^{2}$ Clifford Lynch, "Institutional Repositories: Essential Infrastructure for Scholarship in the Digital Age," portal: Libraries and the Academy 3 (April 1, 2003): 327-36, https://doi.org/10.1353/pla.2003.0039. 
${ }^{3}$ Soohyung Joo, Darra Hofman, and Youngseek Kim, "Investigation of Challenges in Academic Institutional Repositories: A Survey of Academic Librarians," Library Hi Tech 37, no. 3 (January 1, 2019): 525-48, https://doi.org/10.1108/LHT-12-2017-0266.

${ }^{4}$ J. J. Branin, "Institutional Repositories," in Encyclopedia of Library and Information Science, ed. M. A. Drake (Boca Raton, FL: Taylor \& Francis Group, 2005): 237-48; Lynch, "Institutional Repositories."

${ }^{5}$ Raym Crow, “The Case for Institutional Repositories: A SPARC Position Paper," ARL Bimonthly Report 223, August 2002: 7; Lynch, "Institutional Repositories."

${ }^{6}$ Dorothea Salo, “Innkeeper at the Roach Motel," December 11, 2007, https://minds.wisconsin.edu/handle/1793/22088.

${ }^{7}$ Jihyun Kim, “Motivations of Faculty Self-Archiving in Institutional Repositories," Journal of Academic Librarianship 37, no. 3 (May 1, 2011): 246-54, https://doi.org/10.1016/i.acalib.2011.02.017; Deborah E. Keil, "Research Data Needs from Academic Libraries: The Perspective of a Faculty Researcher," Journal of Library Administration 54, no. 3 (April 3, 2014): 233-40, https://doi.org/10.1080/01930826.2014.915168.

8 Trevor Owens, “The Theory and Craft of Digital Preservation," LIS Scholarship Archive, July 15, 2017, https://doi.org/10.31229/osf.io/5cpit.

${ }^{9}$ E.g., Joo, Hofman, and Kim, "Investigation of Challenges in Academic Institutional Repositories."

${ }^{10}$ Sarah Hare and Jenny Hoops, "Furthering Open: Tips for Crafting an IR Deposit Service," October 26, 2018, https://scholarworks.iu.edu/dspace/handle/2022/22547; James Powell, Martin Klein, and Herbert Van de Sompel, "Autoload: A Pipeline for Expanding the Holdings of an Institutional Repository Enabled by ResourceSync,” Code4Lib Journal, no. 36 (April 20, 2017), https://journal.code4lib.org/articles/12427; Carly Dearborn, Amy Barton, and Neal Harmeyer, "The Purdue University Research Repository: HUBzero Customization for Dataset Publication and Digital Preservation," OCLC Systems \& Services, February 1, 2014, https://docs.lib.purdue.edu/lib fsdocs/62.

${ }^{11}$ Clifford Lynch, "Updating the Agenda for Academic Libraries and Scholarly Communications," College \& Research Libraries 78, no. 2 (February 2017): 126-30, https://doi.org/10.5860/crl.78.2.126.

${ }^{12}$ Lynch, “Updating the Agenda,” 128.

13 Diane Walker, “Hesburgh/Snite Mellon Grant," October 31, 2018, https://doi.org/10.17605/OSF.IO/CUSMX.

${ }^{14}$ Hrafnhildur Sif Sverrisdottir, Helgi Thor Ingason, and Haukur Ingi Jonasson, "The Role of the Product Owner in Scrum-Comparison between Theory and Practices," in "Selected Papers from the 27th IPMA (International Project Management Association), World Congress, Dubrovnik, Croatia, 2013," special issue, Procedia-Social and Behavioral Sciences, 119 (March 19, 2014): 257-67, https://doi.org/10.1016/j.sbspro.2014.03.030. 
${ }^{15}$ Salo, "Innkeeper."

${ }^{16}$ Carolyn Ten Holter, "The Repository, the Researcher, and the REF: 'It's Just Compliance, Compliance, Compliance'," Journal of Academic Librarianship 46, no. 1 (January 1, 2020): 102079, https://doi.org/10.1016/i.acalib.2019.102079.

${ }^{17}$ Don Brower et al., 'On Institutional Repositories, 'Beyond the Repository Services,' their Content, Maintainers, and Stakeholders," Against the Grain, 32 (1), https://against-thegrain.com/2020/04/v321-atg-special-report-on-institutional-repositories-beyond-therepository-services-their-content-maintainers-and-stakeholders/.

${ }^{18}$ Bethany Nowviskie, "On Capacity and Care," October 4, 2015,http://nowviskie.org/2015/oncapacity-and-care/; Ruth Kitchin Tillman, "Who's the One Left Saying Sorry? Gender/Tech/Librarianship," April 6, 2018, https://ruthtillman.com/post/whos-the-one-leftsaying-sorry-gender-tech-librarianship/.

${ }^{19}$ Dale Askey and Jennifer Askey, "One Library, Two Cultures” (Library Juice Press, 2017), https://macsphere.mcmaster.ca/handle/11375/22281; Rafia Mirza and Maura Seale, "Dudes Code, Ladies Coordinate: Gendered Labor in Digital Scholarship,” October 22, 2017, https://osf.io/hj3ks/. 